\title{
Ensino da teoria da relatividade em Sobral (CE): uma pesquisa com professores e alunos egressos do Ensino Médio
}

\author{
Antônio Nunes de Oliveira \\ Instituto Federal de Educação, Ciência e Tecnologia do Ceará, campus Sobral/Grupo de Pesquisas \\ em Física Aplicada e Docência (GFAD) \\ (profantuness@gmail.com) \\ Isaque Almeida Bezerra \\ Bolsista PET. Instituto Federal de Educação, Ciência e Tecnologia do Ceará, campus Sobral \\ (isaquealmeidabezerra@gmail.com) \\ Wilton Bezerra de Fraga \\ Instituto Federal de Educação, Ciência e Tecnologia do Ceará, campus Sobral/Grupo de Pesquisas \\ em Física Aplicada e Docência (GFAD) \\ (wilton@fisica.ufc.br)

\begin{abstract}
Marcos Cirineu Aguiar Siqueira
Instituto Federal de Educação, Ciência e Tecnologia do Ceará, campus Sobral

(mcirineu@gmail.com)
\end{abstract}

\begin{abstract}
Resumo: Em 2016, veio a público a primeira detecção de ondas gravitacionais, mais uma das previsões da Teoria da Relatividade Geral, fato este que, aliado a aplicações como as que envolvem - Sistema de Posicionamento Global, ou GPS (sigla de Global Positioning System), torna inquestionável a necessidade de que todos entendam os conceitos e pressupostos básicos desse notável ramo da Física Moderna. Neste trabalho, utilizou-se uma pesquisa de campo, implementada com o uso de questionários, cujos públicos envolvidos foram professores e alunos egressos do Ensino Médio. A finalidade era investigar a situação do ensino da Teoria da Relatividade em SobralCE, cidade palco da observação do eclipse solar de 29 de maio de 1919, cujas imagens possibilitaram comprovar outra previsão da Relatividade Geral - a curvatura da luz pela gravidade. Os resultados indicam a necessidade de reformulação do currículo escolar, possibilitando uma maior aproximação da equitatividade nas abordagens dos conteúdos clássicos, modernos e contemporâneos. Ademais, os professores consideram que Sobral, por causa do seu envolvimento nas observações históricas, deve ter um compromisso maior com o ensino de Relatividade, no sentido de garantir a preservação da memória dos fatos científicos locais relevantes na história da ciência.
\end{abstract}

Palavras-chave: Ensino; Física; Sobral- CE; Relatividade.

\section{Teaching of the relativity theory in Sobral (CE): a research with teachers and high school graduated students}

\begin{abstract}
Due to the frequent applications of the Relativity Theory, the need for everyone to understand their concepts and basic assumptions is undoubtable. In this work, we used a field research implemented with the use of questionnaires, involving teachers and high school students, to investigate how the teaching of the Relativity Theory happens in Sobral-CE, which is the city where one of the experiments that came to prove the Theory of General Relativity took place. The literature and the field research indicate the need to reformulate the school curriculum so that the teaching of classical physics is no longer the focus of high school physics classes, allowing a fairer approach of classical, modern and contemporary contents. Furthermore, teachers consider that, because Sobral
\end{abstract}


was historically involved in the experiment that helped to prove the Theory of General Relativity, it should have a greater commitment to its teaching, in order to guarantee the preservation of the memory of the local scientific facts that are relevant in the history of science.

Key-words: Teaching; Physics; Sobral-CE; Relativity.

\section{INTRODUÇÃO}

Pesquisas na área do Ensino de Física vêm constatando a necessidade de reformulação da sua grade curricular para o Ensino Médio (EM), com o argumento de que a mesma ainda está voltada quase que exclusivamente para a compreensão dos fenômenos abordados pela Física Clássica ( $F C$ ) em detrimento de conhecimentos ligados à Teoria da Relatividade Especial (TRE), Teoria da Relatividade Geral (TRG), Física Quântica e Física Nuclear, bem como as aplicações tecnológicas decorrentes dos resultados dessas teorias.

$\mathrm{Na}$ verdade, a prática escolar usual exclui tanto o nascimento da ciência, como a entendemos, a partir da Grécia Antiga, como as grandes mudanças no pensamento científico ocorridas na virada deste século e as teorias daí decorrentes. A grande concentração de tópicos se dá na física desenvolvida aproximadamente entre 1600 e 1850. Além disso, dificilmente se cumpre toda essa programação. É comum os programas mais completos de física no $2^{\circ}$ grau se reduzirem apenas à Cinemática, Leis de Newton, Termologia, Óptica Geométrica, Eletricidade e Circuitos Simples. Assim, os conteúdos que comumente obrigamos sob a denominação de Física Moderna não atingem os nossos estudantes. Menos ainda os desenvolvimentos mais recentes da Física Contemporânea. O que se pode esperar de uma física escolar que esteja tão descompassada/defasada no tempo? (TERRAZZAN, 1992, p. 209210).

Concordando com Terrazzan (1992), Agostin (2008) e Renner e Krueger (2016) afirmam que o Ensino de Física no EM é deficiente, limitando-se à abordagem da Física Clássica, na qual os conteúdos encontram-se descompassados com relação à realidade dos alunos, além de ser geralmente marcado por abordagens teóricas e descritivas cujas metodologias empregadas pelos professores não têm gerado os efeitos desejados.

Para Terrazzan (1992), segue-se, atualmente, uma sequência de conteúdos ditada por manuais estrangeiros de Ensino de Física que eram utilizados no século passado e que não têm justificativa explícita para existirem. As variações são mínimas, além de manterem excluída toda a Física desenvolvida no século XX e, 
consequentemente, a desenvolvida no século atual. Concordando com Terrazzan, Cruz afirma que:

A Física no ensino médio não tem acompanhado os avanços tecnológicos dos séculos XX e XXI. O currículo se mostra em parte desatualizado e descontextualizado. Neste sentido, pesquisas vêm sendo desenvolvidas na tentativa de aproximar essas duas realidades, promovendo assim um maior significado para as aulas de ciências. Uma das alternativas utilizadas é a inserção de tópicos de Física Moderna e Contemporânea (FMC) no Ensino Médio (CRUZ, 2009, p.1).

Dentro do discurso da necessidade de atualização curricular, surgem pesquisas como as de Terrazzan (1992), Ostermann e Moreira (2000), Agostin (2008), Cruz (2009), Oliveira e Almeida (2013), Renner e Krueger (2016), que, tentando superar o problema, propõem a inserção de tópicos de Física Moderna e Contemporânea (FMC) no ensino como forma de despertar, no aluno, o senso crítico, aproximar a Física ensinada na escola daquela vivenciada em seu cotidiano, possibilitar seu contato com a pesquisa atual em Física e a compreensão das tecnologias dela oriundas como uma maneira de atraí-lo para a carreira científica, bem como disseminar os conhecimentos que a ciência e suas tecnologias propiciam à população.

Cruz (2009) defende a inserção de conteúdos de FMC desde o Ensino Fundamental. Na visão dele, utilizar a História da Ciência seria uma alternativa para esse tipo de abordagem já no $9^{\circ}$ ano. Para que a transposição desse tipo de conteúdo seja viável, faz-se necessária, entre outros fatores, a produção de materiais apropriados, que, segundo Ausubel (2003), devem ter significado lógico para o aluno e, ao mesmo tempo, ser potencialmente significativos; isto é, materiais que possam ser ancorados a ideias relevantes que já existem na estrutura cognitiva do aprendiz e que possam ser assimiladas ou modificadas a partir dessa interação.

Segundo Guerra, Braga e Reis (2007), os livros didáticos evoluíram, uma vez que as novas edições de algumas coleções passaram a incluir, no último volume, temas de Física Moderna, como a Física Relativística, a Física do mundo microscópico e a Cosmologia. Entretanto, a Física Clássica e o formalismo matemático continuam sendo o foco dos livros didáticos e dos exames de seleção para universidades.

O tema continua excluído da maioria dos exames de vestibulares nacionais. Apesar desse não ser o elemento norteador do ensino médio, o privilégio atribuído à física clássica e ao formalismo matemático a ela inerente por parte desses exames reforça a 
resistência de muitos educadores em ampliar a abordagem da física

para além do século XIX (GUERRA; BRAGA; REIS, 2007, p. 575).

Durante uma pesquisa sobre inserção da TRE no EM, realizada por Oliveira e Almeida (2013), um professor comenta, ao responder ao questionário, sobre o livro adotado e como o assunto de Física Moderna (FM) nele é incluído. Em suas palavras:

Leciono apenas em escola de Ensino Médio, onde foi adotado o livro Física- Ciência e Tecnologia, de Carlos Magno A Torres; Nicolau Gilberto Ferraro e Paulo Antônio de Toledo Soares. Faço uso de outros livros didáticos, mas todos em nível de Ensino Médio. A coleção a que me referi apresenta um tópico sobre Física Moderna no livro 3, no último capítulo, aquele que nunca dá tempo ver (risos). Os livros são adequados em boa parte (OLIVEIRA; ALMEIDA, 2013, p.112).

Os resultados de pesquisas em Ensino de Física apontam para um cenário onde os currículos priorizam o ensino de Física Clássica. A partir disso, os estudantes saem do Ensino Médio sem o domínio necessário de conhecimentos de FMC e, embora os livros didáticos tenham incorporado assuntos da Física produzida a partir do início do século XX, a abordagem de FMC no Ensino Médio ainda é deficitária.

Convém destacar que propostas para implementação de conteúdos de FMC no Ensino Médio, em especial da Teoria da Relatividade (TR $)^{1}$, são encontradas em diversos trabalhos na literatura, a exemplo dos de Castilho (2005), Guerra, Braga e Reis (2007), Oliveira e Almeida (2013), Rodrigues, Sauerwein e Sauerwein (2014), Sá (2015), Freire e Charret (2015) e Riboldi e Studart (2015). Segundo Sá (2015), o nível de aprendizado dos conceitos relativísticos demonstrados pelos alunos em avaliações não é menor do que aqueles de Mecânica Clássica que são tradicionalmente ensinados no Ensino Médio.

Quanto às possíveis abordagens da TR que podem ser concretizadas no nível médio, encontramos na pesquisa de Castilho (2015) uma proposta de sequência didática voltada à introdução conceitual da TRE usando recursos computacionais, com destaque para animações originais desenvolvidas no âmbito da pesquisa. Já Guerra (2007) propõe o uso da abordagem histórico-filosófica da ciência para o

1 O termo Teoria da Relatividade (TR) é usado aqui para se referir à Teoria da Relatividade Especial (TRE), publicada em 1905 por Albert Einstein, e à Teoria da Relatividade Geral (TRG), publicada pelo mesmo autor em 1915, sendo esta última comprovada através da observação do Eclipse Solar de 1919. 
ensino tanto da TRE quanto da TRG. Destaca-se, ainda, a importância de abordagens interdisciplinares onde diversas produções culturais possam ser discutidas em conjunto com a ciência. Na pesquisa de Oliveira e Almeida (2013), durante uma proposta para inserção da TRE na qual os conteúdos são distribuídos ao longo das três séries do Ensino Médio, os autores usam, como metodologia, a abordagem histórico-filosófica e cultural juntamente com o modelamento matemático, o qual, para essa teoria, mostrou-se viável, tendo em vista o fato da Matemática necessária ser básica - aquela ensinada em séries anteriores. Além disso, utilizaram-se, nas abordagens, animações, filmes, e letras de músicas que se relacionavam ao assunto que ia sendo discutido.

No que diz respeito ao ensino da TR, considera-se que, por razões históricas, ela deva ser tratada partindo-se dos fundamentos históricos, conceituais e experimentais, focando na transição do clássico para o relativístico onde as contribuições de cientistas como Lorentz, Michelson e Poincaré não podem ser desprezadas. Devido à maior parte das propostas atuais estarem voltadas especialmente para o ensino da Teoria da Relatividade Especial, a qual possui um formalismo matemático bastante acessível aos alunos desse nível de ensino, optouse por focar a pesquisa no ensino da Teoria da Relatividade em si, o que inclui tratamentos da TRE e da TRG e, a partir daí, através de uma pesquisa realizada in loco, averiguar como esse tratamento ocorre, se os alunos chegam a estudar ambas as teorias da relatividade e se, de fato, devido ao experimento de 1919, cujas memórias fazem parte do patrimônio histórico da cidade (e têm sido preservadas através de um museu dedicado ao Eclipse), os professores atribuem a Sobral um maior compromisso com o ensino e a divulgação da Teoria da Relatividade.

\section{METODOLOGIA}

A pesquisa realizou-se mediante aplicação de questionários previamente elaborados e submetidos a dois públicos diferentes: alunos egressos do EM e professores de Física de escolas públicas e particulares, também de EM, na cidade de Sobral-CE. Seu objetivo básico foi propiciar uma visão ampla do cenário em estudo e analisar criticamente as respostas dos questionados quanto à qualidade e à amplitude do ensino da TR em Sobral. Já do ponto de vista metodológico, ela 
possui caráter qualitativo, descritivo e transversal, uma vez que os dados obtidos descrevem conhecimentos e opiniões na realidade presente da comunidade escolar. Com isso, a realização do presente trabalho dividiu-se em duas etapas: na primeira, a pesquisa envolveu os alunos egressos do EM através da aplicação de um questionário; na segunda, aplicou-se o questionário a professores também do EM. Toda pesquisa ocorreu no município de Sobral, com o objetivo de analisar como vem se constituindo o ensino da TR nesta cidade. Além disso, buscou analisar se o experimento de 1919, marco histórico de grande impacto, vem remetendo os professores a uma postura de maior responsabilidade em relação ao ensino da TR e, os alunos, a uma maior curiosidade pelo tema.

\section{Primeira etapa: Pesquisa com os alunos egressos do Ensino Médio}

De início, elaborou-se um questionário com seis questões direcionadas aos egressos do EM, tendo, como intuito, averiguar se os mesmos sabiam quem foi Albert Einstein, se possuíam conhecimento prévio de TR e, em caso afirmativo, onde o adquiriram. Caso houvesse sido na escola, como avaliavam a metodologia utilizada pelo professor?

A pesquisa ocorreu, em sua maior parte, no pátio do bloco didático do Instituto Federal de Educação, Ciência e Tecnologia do Ceará, campus de Sobral (IFCE Sobral), com alunos do Instituto e, também, da Universidade Estadual do Vale do Acaraú (UVA), sendo esses estudantes oriundos de cursos técnicos, superiores e pré-universitários. A amostra de alunos que iriam responder ao questionário foi tomada de forma aleatória, levando-se em consideração somente que fossem egressos de escolas dos setores público e privado, a fim de que as duas realidades pudessem ser confrontadas.

\section{Segunda etapa: Pesquisa com professores do Ensino Médio}

$\mathrm{Na}$ segunda etapa, elaborou-se outro questionário, desta vez com cinco perguntas direcionadas aos professores do nível médio. Neste, os professores responderam a algumas perguntas relacionadas às suas carreiras profissionais e suas formações pessoais, sempre visando ao objetivo maior: tomar conhecimento se, de fato, eles lecionavam conteúdos relacionados à Teoria da Relatividade e, em caso afirmativo, compreender como era feita a abordagem para seus alunos do EM. 
O questionário foi respondido por dez profissionais, também escolhidos de forma aleatória. Procurou-se, contudo, elencar docentes das duas redes de ensino que lecionassem nas escolas dos alunos envolvidos.

\section{RESULTADOS E DISCUSSÃO}

Os resultados da investigação são apresentados a seguir em dois momentos distintos. O primeiro momento corresponde à pesquisa com alunos, e o segundo momento corresponde à pesquisa com professores.

\section{Pesquisa com Alunos Egressos do Ensino Médio}

A tabela 1 mostra as escolas nas quais os alunos participantes da pesquisa concluíram o EM, distinguindo-as entre estadual-particular e urbana-distrital.

Tabela 1 - Relação dos alunos pesquisados e das escolas nas quais eles concluíram o Ensino Médio.

\begin{tabular}{l|c|c}
\hline \multicolumn{1}{c|}{ NOME DA ESCOLA } & TIPO & NÚMERO DE ALUNOS \\
\hline $\begin{array}{l}\text { E.E.F.M Mons. José } \\
\text { Gerardo Ferreira Gomes }\end{array}$ & Estadual - Urbana & 02 \\
\hline Colégio Luciano Feijão & Particular - Urbana & 08 \\
\hline $\begin{array}{l}\text { E.E.M Agostinho Neres } \\
\text { Portela }\end{array}$ & Estadual - Distrital & 02 \\
\hline $\begin{array}{l}\text { E.E.M Dep. Cesário Barreto } \\
\text { Lima }\end{array}$ & Estadual - Distrital & 08 \\
\hline Colégio José Romão & Particular - Urbana & 04 \\
\hline Dom José tupinambá da & Estadual - Urbana & 03 \\
Frota(Estadual) & Particular - Urbana & 03 \\
\hline Colégio Maria Imaculada & Particular-Urbana & 02 \\
\hline Colégio Coração de Jesus & Estadual- Distrital & 02 \\
\hline $\begin{array}{l}\text { E.E.M Israel Leocadio de } \\
\text { Vasconcelos }\end{array}$ & Estadual - Urbana & 04 \\
\hline E.E.M Prof. Arruda & Particular - Urbana & 02 \\
\hline Colégio Farias Brito & Estadual - Urbana & 04 \\
\hline E.E.F.M Prof. Luís Felipe & Particular - Urbana & 03 \\
\hline Colégio Santa Ana & Estadual - Distrital & 04 \\
\hline E.E.M. Dr. José Euclides & & 03 \\
Ferreira Gomes Jr. & Estadual - Urbana & 03 \\
\hline E.E.M. Ayres de Sousa & Estadual - Urbana & \\
\hline E.E.P. Dom Walfrido & Particular - Urbana & 03 \\
Texeira Vieira (Liceu) & & \\
\hline Escola São Francisco de \\
Assis
\end{tabular}

Fonte: Crédito dos autores. 
Conforme a tabela 1, participaram da pesquisa estudantes da área urbana e rural, fato que pode contribuir com uma visão amplificada que espelhe a realidade do ensino de TR nesse município. Como é possível verificar na tabela 1, a pesquisa realizada com os estudantes egressos do EM envolveu a coleta de dados entre um grupo de sessenta alunos em um universo de dezessete escolas, dentre as quais dez são públicas e sete, particulares. A maior parte dos participantes encontram-se em uma faixa etária entre 18 e 25 anos. O fato de escolas particulares distritais não aparecerem na pesquisa deve-se ao fato de, nos distritos de Sobral, não existirem escolas particulares de EM.

A primeira pergunta a ser respondida pelos alunos no questionário foi a seguinte: "Você já ouviu falar de Albert Einstein?". Sem muita surpresa, a resposta foi unânime: todos afirmaram que sim, corroborando quão grande é sua popularidade. No entanto, no ato da aplicação do questionário, alguns se questionavam onde e/ou em qual situação haviam ouvido algo a respeito do cientista.

A pergunta seguinte foi de encontro às respostas do item anterior para aqueles alunos que afirmaram já ter escutado falar de Einstein, mas que não sabiam onde. Ao serem indagados se tinham algum conhecimento a respeito da TR, apenas oito, dos sessenta alunos questionados, responderam não saber nada a respeito - o que representa $13 \%$ dos participantes da pesquisa. Dos oito que não tinham conhecimento de relatividade, somente três eram provenientes de escolas particulares. Uma análise mais acurada leva-nos à seguinte justificativa: o ensino público, muitas vezes, oferece uma maior restrição aos conteúdos na abordagem do mundo físico, pois o número de aulas destinadas a essa disciplina é inferior à carga horária da mesma quando ministrada em escolas particulares. Além disso, os alunos de escolas públicas geralmente chegam com muita deficiência, exigindo do professor a retomada de conteúdos a fim de que eles possam ter um aprendizado próximo do que lhes é desejável.

A figura 1 mostra um gráfico comparativo entre o número de estudantes que responderam ter conhecimento acerca da TR e aqueles que afirmam não ter conhecimento sobre ela. 


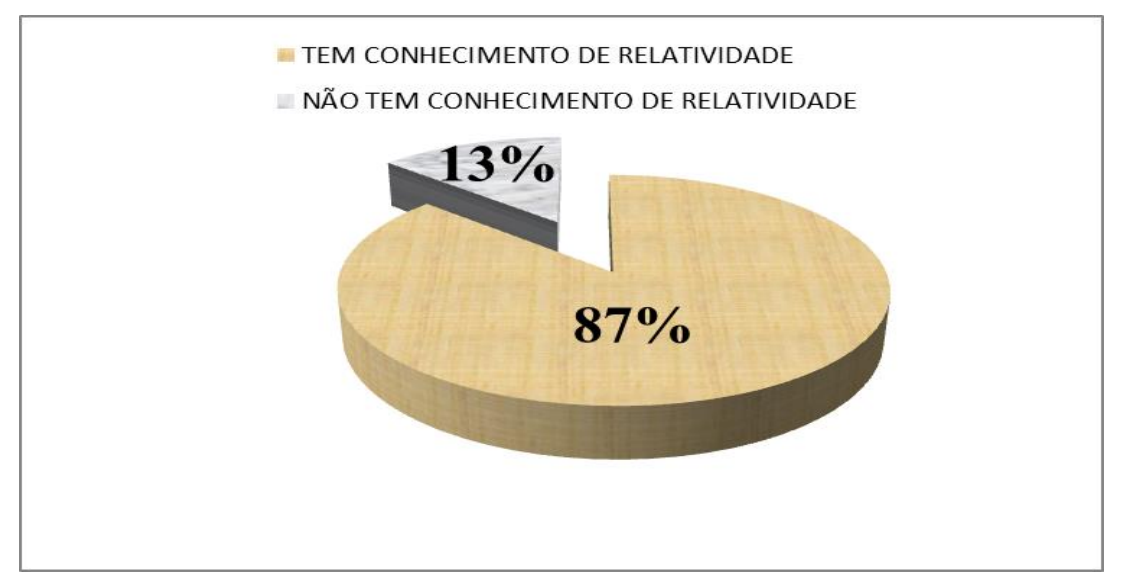

Figura 1: Gráfico comparativo entre a quantidade de alunos que julgam ter conhecimento de relatividade e aqueles que afirmam não ter. Fonte: Crédito dos autores.

Embora todos os alunos tenham escutado falar de Albert Einstein, somente $13 \%$ deles responderam não saber nada a respeito da TR. Isso nos leva a pensar que estes certamente ouviram falar o nome Einstein como uma referência a pessoas inteligentes, ou mesmo associada ao famoso jargão popular de que "tudo é relativo"2; ou ainda, associado ao nome teoria da Relatividade, entretanto sem esclarecimentos adicionais.

Dando continuidade aos questionamentos com os egressos do EM, direcionouse uma pergunta aos $87 \%$ dos alunos que responderam ter conhecimento acerca da TR. O objetivo era saber onde eles adquiriram esse conhecimento, se a escola estava cumprindo o seu papel de instruir seus alunos ou se outros meios estavam preenchendo a lacuna existente. No questionário proposto, existiam quatro opções de marcar: "Na escola", "Na internet", "Em conversas" e "De outras formas". Nesta última opção, havia um espaço no questionário para especificar. Dentre os cinquenta e dois alunos que responderam ao questionamento, 67\% disseram que estudaram a respeito na escola, $23 \%$ disseram ter visto o assunto na internet, $6 \%$ disseram ter ouvido a respeito durante conversas e $4 \%$ responderem haver sido de outras formas, conforme os dados da figura 2.

$2 \quad$ Nota-se que a Teoria da Relatividade não parte do pressuposto de que tudo é relativo. Pelo contrário, ela parte de seus dois postulados que apregoam ser a velocidade da luz uma medida absoluta, independentemente do observador inercial que afere seu valor, e que as leis da Física preservam sua forma ao se passar de um referencial a outro. 


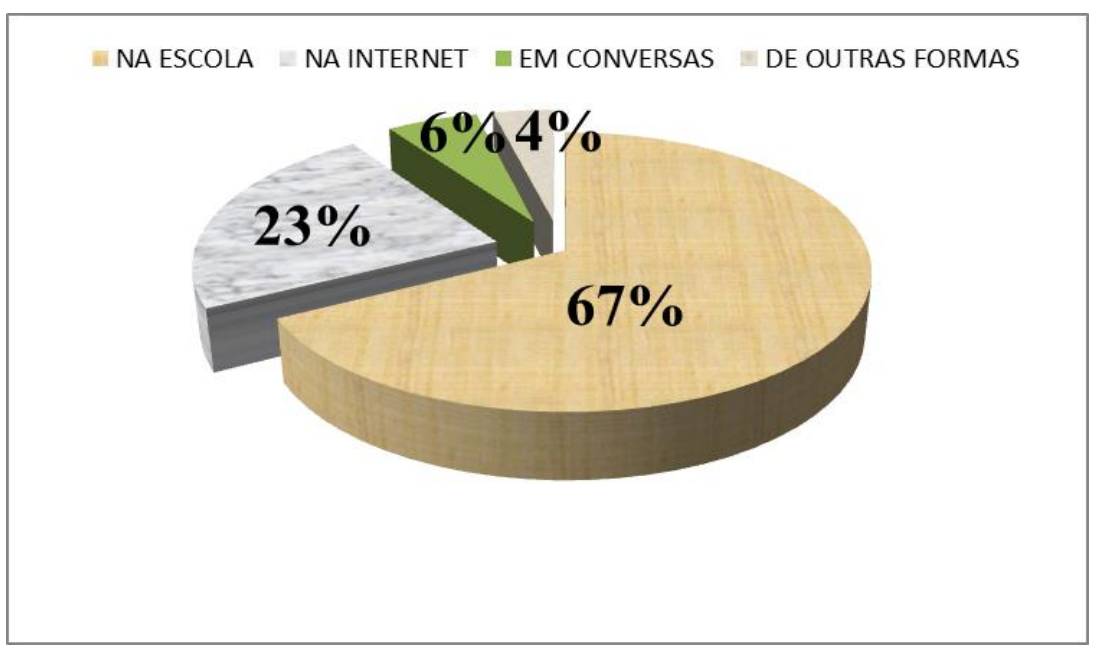

Figura 2: Onde os alunos egressos do Ensino Médio adquirem conhecimento sobre a TR . Fonte: Crédito dos autores.

Os resultados revelam que os alunos de Sobral, em sua maioria, estão tendo contato com conteúdos da TR em sala de aula, sendo que apenas $33 \%$ alegam adquirir esses conhecimentos por meio de outros canais. A pesquisa revelou, ainda, que os alunos têm curiosidade sobre o assunto e que buscam respostas às suas indagações na internet, geralmente através de vídeos de curiosidades no Youtube. Para alguns deles, o conhecimento acerca de assuntos como dilatação do tempo e contração espacial chegam por meio de conversas informais com os professores e/ou com os próprios colegas. Segundo os alunos, outras formas de suprir um pouco suas necessidades pela aprendizagem desse tipo de conteúdo são os programas educacionais e as aulas de história.

Por fim, solicitou-se aos educandos que avaliassem as metodologias utilizadas pelo professor durante as aulas sobre a TR. A pergunta foi direcionada para os 35 alunos que, no questionamento anterior, deram como resposta terem adquirido o conhecimento sobre a TR na sua escola. Dentre eles, $11 \%$ acharam insuficientes o domínio do assunto apresentado pelo professor e a metodologia de ensino por ele empregada, 14\% acharam razoáveis, 29\% julgaram bons e 46\% consideraram excelentes. Esses dados estão representados na figura 3. 


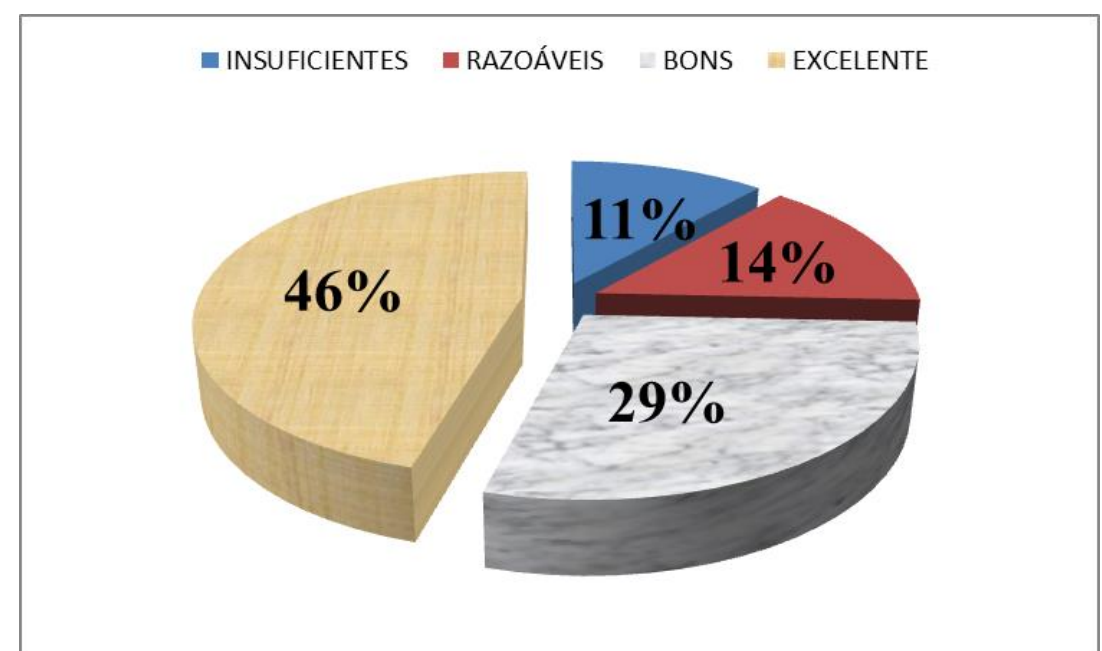

Figura 3: Avaliação dos alunos quanto ao domínio e metodologias empregadas pelo professor ao lecionar conteúdo de TR. Fonte: Crédito dos autores.

Apenas $11 \%$ dos alunos da pesquisa que estudaram relatividade no EM consideram as metodologias empregadas na transposição do conteúdo insuficientes e que as formas de abordagem não costumam facilitar a compreensão. Para outros $46 \%$, as metodologias utilizadas eram excelentes. Segundo estes, os professores traziam, em suas aulas, instrumentos que facilitavam a compreensão, apresentando aplicações por meio de exemplos práticos. A exposição do conteúdo era mediada pelo uso do datashow, com animações e vídeos ilustrativos dos fenômenos estudados. Alunos das escolas particulares citaram, ainda, como facilitadora da aprendizagem, a exposição do professor com a utilização da lousa digital. Fica claro, neste ponto, que o uso de tecnologias na educação, se bem aplicado, é valorizado pelos discentes, podendo revelar-se como instrumentos facilitadores no processo de ensino- aprendizagem.

Convém destacar que, devido a Sobral ter sediado uma das observações que culminaram com a comprovação da TRG de Albert Einstein (vide Crispino (2016) e Will (2014)), a cidade ganhou um monumento, o "Museu do Eclipse", disponível para visitação da comunidade. Esse museu tem desempenhado um importante papel junto à comunidade, contribuindo com a divulgação científica e a preservação do patrimônio científico, histórico e cultural de Sobral.

Na figura 4 é possível visualizar parte da cidade em que se encontra o museu. 


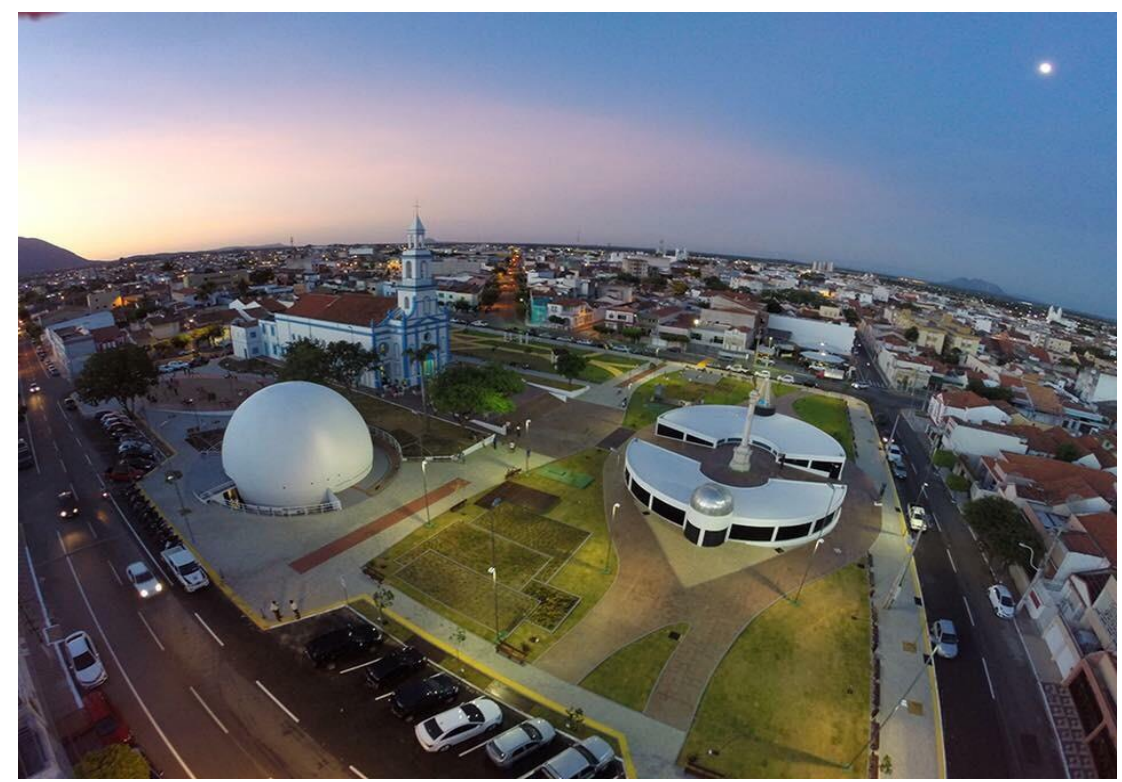

Figura 4: Museu do Eclipse em Sobral. Fonte: jf.vpeventos.com.

Ao longo dos anos, tornou-se habitual que as escolas acabem levando seus alunos para visitarem o museu - uma oportunidade para os estudantes e para a própria população conhecerem mais sobre fatos científicos e históricos que envolveram sua cidade e, consequentemente, para aprenderem sobre a TRG. Apesar disso, transparece que, embora o museu tenha cumprido um importante papel na formação científica, histórica e cultural dos estudantes que por ele passaram, os conhecimentos básicos a respeito da Teoria da Relatividade precisam chegar ao aluno por intermédio da escola.

\section{Pesquisa com professores do Ensino Médio}

A pesquisa realizou-se com dez professores, sendo cinco deles de escolas particulares. Em Sobral, geralmente, ou os professores dedicam-se exclusivamente às escolas particulares - que Ihes possibilitam um melhor salário e consomem todo o seu tempo de trabalho - , ou então lecionam em escolas públicas, que lhes oferecem maior facilidade de ingresso no mundo de trabalho, uma vez que têm maior número de vagas disponíveis.

Dentre os professores participantes da pesquisa, apenas um não possuía Licenciatura em Física, além de também não a cursar. No entanto, o mesmo possuía curso superior em Tecnologia da Construção Civil, com especialização em Ensino de Matemática e Gestão Escolar, estando há mais de quatro anos como professor de Física da rede particular de ensino. Todos já tinham mais de três anos de experiência no ensino de Física para alunos do EM. 
Os resultados possibilitaram a constatação de que $90 \%$ dos professores entrevistados ou eram graduados na área específica ou estavam em processo de formação, o que é algo significativo, haja vista que há uma enorme carência de profissionais da área no mercado de trabalho. Esse resultado certamente é consequência de existirem duas graduações em Física na cidade de Sobral, oferecidas pelo IFCE Sobral e pela UVA.

Observou-se que $70 \%$ dos professores que responderam ao questionário já haviam ensinado conteúdos da TR para seus alunos. Apenas três deles responderam que não abordavam os conteúdos da TR em suas aulas no EM. Uma das principais justificativas apresentadas para tal fato foi de havia pouco tempo para as aulas de Física na escola. Além disso, as escolas priorizam conteúdos de Mecânica Clássica em detrimento dos de FMC porque geralmente têm, como principal objetivo, a aprovação de seus alunos nos vestibulares. No entanto, conteúdos de FMC frequentemente não aparecem no principal exame de seleção para Universidades e Institutos Federais (IFs) - o ENEM -, o que faz com que fiquem em segundo plano. Esse fato não deveria ocorrer, uma vez que a função social da escola é preparar o indivíduo para a vida em sociedade e torná-lo apto a assumir funções no mercado de trabalho.

Nos livros didáticos, tais conteúdos estão situados no último capítulo e, geralmente, a sobrecarga de conteúdos não permite sua abordagem. Outro ponto citado por um professor, na tentativa de justificar a não abordagem do tema, é que, além dos conteúdos do EM serem extensos, existe o fato de que os educadores da área de exatas geralmente lidam com turmas heterogêneas. Nelas, existem alunos que chegam com uma defasagem de conhecimentos matemáticos muito grande, fazendo com, que muitas vezes, o professor fique limitado a abordagens de determinados conteúdos, uma vez que a matemática é uma ferramenta fundamental para descrição dos fenômenos físicos. Na fala do professor, o "currículo da Física no EM é muito extenso, temos que resumi-lo em 200 dias letivos. Por isso não é possível tratar de assuntos como relatividade e ainda nossos alunos tem uma base muito fraca o que faz com tenhamos que repetir o conteúdo inúmeras vezes e perder um tempo precioso".

Para esse professor, a percepção das deficiências matemáticas e também conceituais geram um atraso no andamento das aulas, uma vez que, para o aluno aprender, necessita abordar o conteúdo mais de uma vez, revendo suas 
metodologias, de modo a possibilitar ao discente uma compreensão do assunto tratado. Em contrapartida, há professores que conseguem abordar, nas suas aulas, o conteúdo de Relatividade Restrita. Nota-se que, geralmente, os profissionais que conseguem abordar assuntos de FMC são aqueles que lecionam em escolas particulares, pois alunos de escolas privadas têm ao seu dispor mais aulas de Física, às vezes chegando ao dobro do número de aulas disponíveis nas escolas públicas. Some-se a isso o fato de as escolas particulares geralmente oferecerem aulas extras para aqueles alunos que participam de olimpíadas.

Entre os cinco professores de escolas públicas que participaram da pesquisa, dois afirmaram conseguir abordar conteúdo de TR em suas aulas, enquanto os demais afirmaram não conseguir. Buscando uma explicação para o fato, percebeuse que os dois lecionam em escolas de tempo integral. Em tais escolas, os alunos ingressam por meio de uma prova de aptidão. Isso leva a crer que os educadores de escolas de tempo integral têm um público presumivelmente com uma boa base educacional, o que pode facilitar o andamento do conteúdo e possibilitar novas abordagens.

Questionados sobre quais conteúdos de TR ensinam no EM, os professores citaram tópicos como: sistemas de coordenadas inerciais, o fenômeno da dilatação do tempo, contração de comprimentos e paradoxo dos gêmeos. Devido à sobrecarga de assuntos, não há tempo hábil para abordar conteúdos como momento relativístico, energia relativística e relação entre massa e energia, muito menos a teoria da Relatividade Geral. Ao serem questionados sobre quais metodologias ou estratégias eram utilizadas ao lecionar conteúdos da TR, as respostas limitaram-se ao uso de fotos e vídeos.

Quando questionados sobre a importância do ensino da TR para estudantes do EM, todos concordaram que abordar o tema Relatividade nessa etapa da educação formal é essencial, e mesmo aqueles professores que afirmaram não realizar tal abordagem concordaram quanto à importância da presença desses conteúdos na formação do seu aluno. Dentre as justificativas fornecidas por eles, destacam-se:

"Considero importante ensinar Relatividade no EM, pois o aluno passa a ter uma noção real das limitações da Física Clássica, assim como percebe que a Física Clássica é um caso particular da Física Moderna, podendo, assim, expandir seus 
conhecimentos, não ficando limitado no pensamento de que a Física possui um conhecimento finito."

"A cidade de Sobral, em especial, deve ter um cuidado maior que as outras no estudo da Relatividade, pois seus moradores devem conhecer melhor a importância dos conhecimentos adquiridos na ciência em decorrência da boa localização, na época, para observações relevantes que marcaram uma nova era no Ensino de Física."

Os docentes de Física do EM, de um modo geral, consideram que, por ter sido historicamente envolvida na comprovação da TRG, como consta em Mourão (1993), Will (2014) e Crispino (2016), Sobral deve ter um compromisso maior com o ensino da TR, no sentido de garantir a preservação da memória e dos fatos científicos locais relevantes à história da ciência.

\section{CONCLUSÕES}

A pesquisa possibilitou reafirmar a conveniência da necessidade de reformulação do currículo escolar da disciplina de Física nos Ensinos Fundamental e Médio, uma vez que pesquisadores da área vêm constatando sucessivamente a necessidade da presença desses conteúdos na formação de um ser crítico e participativo, em uma sociedade cada dia mais industrializada e tecnológica, em que as aplicações da FMC estão cada vez mais presentes no dia a dia da população. A pesquisa com professores apontou claramente a dificuldade dos mesmos em abordar esse tipo de conteúdo, principalmente os de escolas públicas de ensino regular, onde a carga horária da disciplina de Física é bastante reduzida.

Os professores defendem que a forma como o conteúdo de FMC é geralmente distribuído no livro didático destinado a alunos do terceiro ano do EM, ocupando o último capítulo, coloca-o em segundo plano. Segundo a fala de uma professora envolvida na pesquisa de Oliveira e Almeida (2013), o conteúdo é "aquele que nunca dá tempo de ver". Outro fator evidenciado nesse sentido diz respeito às provas que selecionam alunos para as universidades, as quais raramente têm contemplado questões com esses assuntos, o que influencia diretamente na abordagem secundária dada ao referido conteúdo, uma vez que, 
erroneamente, as escolas costumam priorizar os assuntos mais presentes nesses exames.

Dado o exposto acima, uma possível solução que permitiria uma maior abordagem de tópicos de FMC no EM seria elaborar propostas para inserção de seus conteúdos desde o primeiro ano e incrementar os livros didáticos de modo que tais conteúdos saíssem do último capítulo do livro do terceiro ano e passassem a integrar partes de todos os livros contemplados nos três anos do EM. Uma solução desse tipo, pensada particularmente para inserção da TRE, foi proposta por Oliveira e Almeida (2013) ao elaboraram e aplicarem um material didático que distribuía o assunto ao longo das três séries do EM, verificando, ao final da aplicação, a viabilidade da sua proposta.

Embora esse tipo de proposta torne a abordagem de conteúdos de Física Clássica e Física Contemporânea mais homogênea, certamente persistirá o fato de que os conteúdos estruturados nos últimos capítulos do livro do terceiro ano continuarão ausentes nas salas de aula, pois ficou claro que sua abordagem exige um maior número de aulas destinadas à disciplina de Física.

Constatou-se, ainda, que a Teoria da Relatividade Restrita é abordada em salas de aula do EM, entretanto, o conteúdo de Relatividade Geral está ausente, sendo sua abordagem histórica vinculada à história da cidade e estando acessível, em geral, somente para aqueles alunos que têm a oportunidade de participar de uma visitação ao Museu do Eclipse.

Trabalhos futuros poderão ser feitos no sentido de:

- averiguar o conhecimento que a população tem acerca do evento científico observado em Sobral em 1919 e o papel que o Museu do Eclipse tem cumprido no sentido de tornar viva a memória desse marco histórico;

- pesquisar a presença de conceitos de Relatividade nas salas de aula do Ensino Fundamental, elaborando uma proposta de ensino que viabilize sua inserção nessa etapa do contexto escolar, assim como sugere Cruz (2009);

- verificar como tem ocorrido a abordagem da Teoria da Relatividade Geral e do eclipse solar total, observado em Sobral no dia 19 de maio de 1919, durante as aulas de história no EM;

- produzir um estudo comparativo que confronte a realidade do ensino de Física nas escolas públicas de tempo integral com o ensino nas escolas públicas regulares e nas escolas particulares; 
- pesquisar, junto às universidades locais, as matrizes curriculares dos cursos de licenciatura em Física, a fim de saber se estes vêm possibilitando uma formação adequada aos professores para abordagens que envolvam a Física Moderna e Contemporânea;

- elaborar propostas que possam contribuir com avanços na inserção da Teoria da Relatividade Geral durante as aulas de Física do EM.

No caso do Ensino Fundamental. enfatiza-se a ideia de Cruz (2009) de que usar a História da Ciência seja uma forma possível de inserir conteúdos da TR já neste nível de ensino. Acredita-se, ainda, que trechos de filmes e desenhos animados com os quais as crianças têm contato frequente poderiam servir como organizadores prévios, levando os alunos à aprendizagem significativa. Tanto para o Ensino Fundamental quanto para o Médio, faz-se necessário repensar os conteúdos curriculares de maneira que as abordagens de assuntos de Física Moderna e Contemporânea sejam facilitadas já nesses níveis de ensino.

Outro tema de grande impacto local é a Radioatividade, tendo em vista o projeto para extração de Urânio em Santa Quitéria-CE, cidade localizada a 85,7 km de Sobral-CE. Com isso, pesquisas futuras sobre o ensino de FMC poderão verificar a viabilidade da inserção do tópico Radioatividade nas aulas do Ensino Fundamental e Médio através de propostas relacionadas ao ensino contextualizado da Física.

\section{REFERÊNCIAS}

AGOSTIN, A. D. Física moderna e contemporânea: com a palavra professores do ensino médio. Curitiba, 112 p., 2008. Dissertação (Mestrado) - Universidade Federal do Paraná.

AUSUBEL, D. Aquisição e retenção de conhecimentos: uma perspectiva cognitiva. Plátano Editora: 1. Edição, Janeiro de 2003.

CASTILHO, M. I. Uma introdução conceitual à Relatividade Especial no ensino médio. 2005. 143 f. Dissertação (Mestrado) - Curso de Mestrado Profissionalizante em Ensino de Física, Instituto de Física, Universidade Federal do Rio Grande do Sul, Porto Alegre, 2005.

CRISPINO, L. C.B.; LIMA, M. C. Amazonia Introduced to General Relativity: The May 29, 1919, Solar Eclipse from a North-Brazilian Point of View. Birkhauser- Published online: 01 september 2016.

CRUZ, R. S. D.; GUERRA, A. Tópicos de fisica moderna e contemporânea no ensino fundamental. XVIII Simpósio Nacional de Ensino de Física, Vitória ES, 2009. 
FERREIRA, E. G. B.; DAMASIO, F.; RODRIGUES, A. A. Física Moderna e Contemporânea no Ensino Fundamental articulada com o conceito de Física Clássica por meio de unidades de ensino potencialmente significativas (UEPS). Aprendizagem Significativa em Revista/Meaningful learning Revien - V4(1), p29-40, 2014.

FREIRE, J. C.; CHARRET, I. C. Evolução dos conceitos do mundo: uma proposta de inserção da Teoria da Relatividade no Ensino Médio. Mestrado Nacional Profissional em Ensino de Física (MNPEF), Caderno do professor de Física, Lavras-MG, 2015.

GUERRA, A.; BRAGA, M.; REIS, J. C. Teoria da relatividade restrita e geral no programa de mecânica do ensino médio: uma possílvel abordagem. Revista Brasileira de Ensino de Fílsica, v. 29, n. 4, p. 575-583, 2007.

MOURÃO, R. R. de Freitas. Os Eclipses, da superstição à previsão matemática. São Leopoldo: Ed. Unisinos, 1993.

MUSEU do Eclipse em Sobral. Disponível em: <https://jf.vpeventos.com/evento-1Jornada\%20de\%20F\%C3\%ADsica>. Acesso em: 12 de março de 2016.

OLIVEIRA, A. N.; ALMEIDA, C A S. Ensino de Relatividade Especial no Ensino Médio: uma abordagem progressiva. In: Isaías Batista de Lima. (Org.). Didática, Educação Ambiental e Ensino de Ciências e Matemática: Múltiplos Olhares. 1ed.Fortaleza: Editora da Universidade Estadual do Ceará, 2013, p. 107-117.

OSTERMANN, F.; MOREIRA, M. A. Uma revisão bibliográfica sobre a área de pesquisa "Física Moderna e Contemporânea no Ensino Médio". Investigações em Ensino de Ciências, v. 5, p. 23-48, 2000.

RENNER, G. L. P.; KRUEGER, C. Física Moderna e Contemporânea no Ensino Médio: Um estudo acerca dos fatores que interferem na aplicação dos conceitos em sala de aula. $V$ Simpósio Nacional de Ensino de Ciência e Tecnologia. Disponível em: <http://www.sinect.com.br/2016/selecionados.php>. Acesso em: 26 de março de 2017.

RIBOLDI, B. M.; STUDART, N. Relatividade Restrita: games e animações. $1^{\text {a }}$ ed., LavrasMG, 2015.

RODRIGUES, C. M.; SAUERWEIN, I. P. S.; SAUERWEIN, R. A. Uma proposta de inserção da Teoria da Relatividade Restrita no Ensino Médio via estudo do GPS. Revista Brasileira de Ensino de Física, v. 36, n. 1, 1401, 2014.

SÁ, Marcos, R. R. de. Teoria da Relatividade Restrita e Geral ao longo do $1^{0}$ ano do Ensino Médio: uma proposta de inserção. 2015. 318 f. Dissertação (Mestrado) - Curso de Mestrado Nacional Profissional em Ensino de FÍsica, Instituto de Física, Universidade de Brasília, Brasília, 2015.

SILVEIRA, S.; GIRARDI, M. Fotoduino: Um kit experimental com Arduino para o estudo do Efeito Fotoelétrico no Ensino Médio. (Guia de montagem, Utilização e Aplicação), Araranguá, 2016.

TERRAZZAN, E. A. A inserção da física moderna e contemporânea no ensino de física na escola de segundo grau. Caderno catarinense de Ensino de Física, Florianópolis, v. 9, n. 3, p. 209-214, Dezembro 1992. 
WILL, C. M. The 1919 measurement of the deflection of light. Cornell University Library, submetido em 27 de Setembro de 2014. Disponível em:<https://arxiv.org/abs/1409.7812>. Acesso em: 18 de Julho de 2017. 